\title{
Bethe-Salpeter study of cationic dyes: Comparisons with ADC(2) and TD-DFT
}

\author{
Cloé Azarias, ${ }^{1}$ Ivan Duchemin, ${ }^{2,3}$ Xavier Blase, ${ }^{3,4}$ and Denis Jacquemin ${ }^{1,5, a)}$ \\ ${ }^{1}$ CEISAM, UMR CNRS 6230, BP 92208, Université de Nantes, 2, Rue de la Houssinière, \\ 44322 Nantes Cedex 3, France \\ ${ }^{2}$ INAC, SP2M/L_Sim, CEA/UJF Cedex 09, 38054 Grenoble, France \\ ${ }^{3}$ Univ. Grenoble Alpes, Inst NEEL, F-38042 Grenoble, France \\ ${ }^{4}$ CNRS, Inst NEEL, F-38042 Grenoble, France \\ ${ }^{5}$ Institut Universitaire de France, 1 Rue Descartes, F-75231 Paris Cedex 05, France
}

(Received 22 November 2016; accepted 3 January 2017; published online 18 January 2017)

\begin{abstract}
We present a theoretical investigation of the excited-state properties of a large series of structurally diverse arylcarbonium derivatives that are known to be challenging for theoretical models. More specifically, we compare the pros and cons of TD-DFT (TD-M06-2X), ADC(2), and BSE/GW approaches for a large panel of compounds, using two different solvent models. Both 0-0 and vertical transition energies are considered and compared to the experimental values. All approaches reasonably reproduce the auxochromic and acidochromic shifts, although in most cases both TD-DFT and BSE/ $G W$ return larger correlation with experimental values than $\mathrm{ADC}(2)$ for these shifts. In contrast, the absolute transition energies obtained with $\mathrm{ADC}(2)$ tend to be closer to the measurements, TD-DFT using the M06-2X functional largely overestimating the experimental references (by ca. $0.5 \mathrm{eV}$ ), and $\mathrm{BSE} / G W$ providing intermediate values. In addition, we show that the selected solvent model has a significant impact on the results, the corrected linear-response approach providing larger transition energies than its linear-response counterpart. Published by AIP Publishing. [http://dx.doi.org/10.1063/1.4974097]
\end{abstract}

\section{INTRODUCTION}

Arylcarbonium derivatives constitute one of the first successful families of artificial dyes and still remain widely used today. Developed in the 19th century, these cationic compounds have been originally introduced for dyeing textile, due to their extreme brilliance and high color depth, but their applications now extend to a wider range of research fields, including medicine, ${ }^{1}$ biology, ${ }^{2}$ cosmetics, ${ }^{3}$ analytical chemistry, ${ }^{4}$ and electronics. ${ }^{5}$ As illustrated in Figure 1, this class of dyes presents a great structural diversity. They are composed of a formal cationic center but, applying the classical mesomeric theory, the charge can be viewed as delocalized over the whole $\pi$-system that is formed by two or three aromatic rings that are typically functionalized by auxochromic groups. Depending on the nature and position of these substituents, as well as on the nature of the heteroatom (R, X, and $X^{\prime}$ in Figure 1), these dyes can provide a large panel of hues covering the whole visible part of the electromagnetic spectrum. For instance, adding a dimethylamino group at position 4 on the Malachite Green (MG, C.I. Basic Green 4) leads to the Crystal Violet dye (CV, C.I. Basic Violet 3), inducing, as these names suggest, a significant change of color. Likewise, replacing the three $\mathrm{NMe}_{2}$ groups of $\mathrm{CV}$ with $\mathrm{NH}_{2}$ yields the deep-red Pararosaniline dye (C.I. Basic Red 9). The interactions with the surroundings (solvent molecules, fibers, polymers, etc.) also tune the shades of these dyes. Additionally, changing the $\mathrm{pH}$ allows to control the protonation states of the peripheral amine groups

a)Electronic mail: Denis.Jacquemin@ univ-nantes.fr and consequently change their donor character, which, in turn, allows tuning the color (acidochromism) of the arylcarbonium chromophores. ${ }^{6-9}$

Despite their venerable age, the accurate prediction of the UV-visible spectra of these industrially relevant dyes remains both challenging and of interest today. Amongst all ab initio approaches developed for modeling excited-state (ES) properties, the most popular is certainly Time-Dependent Density Functional Theory (TD-DFT) ${ }^{10}$ that has been widely used in its linear-response (LR) adiabatic formulation. ${ }^{11,12}$ Indeed, this theory is now a common theoretical-spectroscopy tool because of the following: (i) it benefitted from the implementation of refined implicit solvation model such as the well-known polarizable continuum model (PCM) that enables one to consider the system in a realistic environment; ${ }^{13}$ (ii) it presents a favorable $\mathcal{O}\left(N^{4}\right)$ formal scaling so that one can model large and diverse compounds in a systematic way; ${ }^{14}$ (iii) analytical geometrical derivative expressions have been obtained and implemented, ${ }^{15-18}$ giving a rapid access to fluorescence properties, $0-0$ energies, and vibronic couplings. ${ }^{19-21}$ Despite all the advantages that TD-DFT offers, it presents some drawbacks such as significant dependency on the exchange-correlation functional (XCF) used $^{22}$ and a failure to deliver accurate transition energies for cyanine-like compounds. ${ }^{22-33}$ This latter limitation is particularly problematic for the arylcarbonium family as the majority of these dyes exhibit electronic transitions similar to those of the standard merocyanines that also present a formal positive charge delocalized on a chain containing an odd number of carbon atoms. Consequently previous TDDFT calculations have provided rather poor results. ${ }^{34,35}$ For 


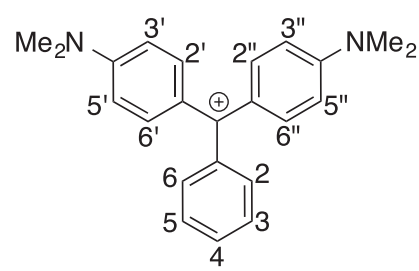

Malachite Green (MG)<smiles>[R]C(c1ccc(N(C)C)cc1)c1ccc(N(C)C)cc1</smiles>

Michler's Hydrol Blue (MHB)

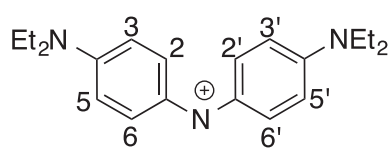

Bindschedler green (BG)

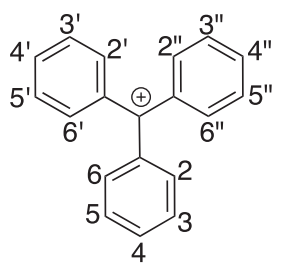

Triphenylmethane cation (TPC)<smiles>c1ccc(Cc2ccccc2)cc1</smiles>

Diphenylmethane cation (DPC)

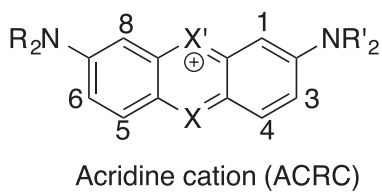

FIG. 1. Structure of selected arylcarbonium dyes with the numbering of the substitution positions.

instance, in the extended benchmark of Ref. 35, the mean absolute deviation (MAD) obtained with the well-known CAMB3LYP ${ }^{36}$ attains $0.25 \mathrm{eV}$ for the $\pi \rightarrow \pi^{\star}$ transitions in neutral dyes whereas for the arylcarbonium family, the error is twice as large. This TD-DFT failure for cyanine-like compounds is now understood, notably by the inadequacy of "standard" TD-DFT to capture differential electron correlation effects that are very large in this class of dyes. ${ }^{25,28-30,33,37,38}$ It is also noteworthy that these large errors cannot be completely cured by "simply" changing the selected exchange-correlation functional due to the relative insensitivity of the TD-DFT response to the functional for cyanine excited-states. For instance, in MG, the TD-DFT vertical transition energies are $2.40 \mathrm{eV}, 2.53 \mathrm{eV}$, and $2.52 \mathrm{eV}$ with B3LYP, LC-BLYP, and CAM-B3LYP, respectively, ${ }^{35}$ whereas for most dyes, going from B3LYP to CAM-B3LYP induces a much bigger upshift.

Amongst all the available wavefunction theories suited to model excited-states, the second-order algebraic diagrammatic construction, $\operatorname{ADC}(2)^{39,40}$ is becoming increasingly used due to its good compromise between accuracy and computational cost. In particular ADC(2) generally delivers transition energies very similar to those obtained with the second-order approximate coupled-cluster singles and doubles model (CC2) for a smaller computational cost. ${ }^{41-43}$ Nevertheless, these approaches present a less favorable $\mathcal{O}\left(N^{5}\right)$ formal scaling with system size than TD-DFT and solvent models coupled to $\mathrm{ADC}(2)$ have only started emerging. ${ }^{44-46}$ For the classical merocyanine dyes, $\mathrm{ADC}(2)$ has been shown to deliver reasonable estimates, ${ }^{30,33}$ but there is, to the best of our knowledge, no application of $\mathrm{ADC}(2)$ to arylcarbonium dyes. Another valuable approach for ES calculations is the Bethe-Salpeter Equation (BSE) ${ }^{47-49}$ formalism that relies on the $G W$ exchangecorrelation self-energy operator and the related occupied and virtual energy levels. ${ }^{50-52}$ This approach conserves the $\mathcal{O}\left(N^{4}\right)$ scaling of TD-DFT while allowing for a significantly more limited dependency on the starting XCF when a (partially) self-consistent $G W$ approach is applied. ${ }^{43,53,54}$ While both
BSE and $G W$ were originally mainly applied to periodic solids using planewave implementations, applications of the BSE formalism to molecular systems have been booming during the last decade. ${ }^{31,32,43,53-82}$ As in the case of $\operatorname{ADC}(2)$, it has been demonstrated that $\mathrm{BSE} / G W$ performs well for merocyanine derivatives, ${ }^{31}$ and this also holds for BODIPY dyes, ${ }^{32}$ but no applications for non-trivial charged dyes appeared yet.

In this framework, we investigate here a large number of arylcarbonium derivatives with TD-DFT, $\operatorname{ADC}(2)$, and $\mathrm{BSE} / G W$, in an effort to obtain accurate theoretical estimates for these dyes. When the emission spectra were experimentally determined, we computed 0-0 energies allowing physically well-grounded comparisons with the experimental values. To the very best of our knowledge, the present study stands as the first work to compare the performances of these three theories to this important class of dyes.

\section{COMPUTATIONAL DETAILS}

All calculations have been performed following a twostep protocol. First, we performed geometry optimization and Hessian calculations using (TD-)DFT, to compute equilibrium geometries and zero-point vibrational energies (ZPVE) of both ground- and excited-states. In the second stage, we determined the gas phase (and solvated for TD-DFT) vertical electronic transition energies at the TD-DFT, ADC(2), and $\mathrm{BSE} / G W$ levels using the geometries obtained in the first step. The solvent effects have been computed with PCM at the TD-DFT level, and the BSE or ADC(2) transition energies have been corrected for solvation using the difference between the "solvated" and gas phase TD-DFT transition energies. This protocol allows for the efficient calculation of the vibronic 0-0 transition energy, sum of the adiabatic transition energy and the differential ZPVE between ground- and excited-states (see Ref. 43 for details). Nevertheless, as the solvent effects on the absorption and emission energies are determined on the basis of TD-DFT (transition or total) densities, it should be noted that when the TD-DFT description of the excited-state is not physically sound, this approximation may induce a significant error.

\section{A. Structural and vibrational calculations}

All the geometry optimization and Hessian calculations have been performed with DFT and TD-DFT using the Gaussian09 program, ${ }^{83}$ tightening self-consistent field $\left(10^{-10}\right.$ a.u. $)$ and geometry optimization $\left(10^{-5}\right.$ a.u.) thresholds, and applying the (99590) pruned integration grid (the so-called ultrafine grid). These calculations relied on the M06-2X hybrid functional $^{84}$ and the $6-31 \mathrm{G}(\mathrm{d}, \mathrm{p})$ atomic basis set that has been shown to be satisfying for the geometry optimizations of arylcarbonium derivatives. ${ }^{34}$ During the force minimizations and Hessian calculations, environmental effects have been accounted for using PCM method, ${ }^{13}$ as implemented in Gaussian09. More precisely, we used the linear-response $\operatorname{approach}^{85,86}$ in its equilibrium (eq) limit.

\section{B. Determination of the transition energies}

We computed the transition energies on the optimal ground-state (GS) and ES geometries, using TD-DFT, 
$\mathrm{ADC}(2)$, and BSE/GW. In this step, the Dunning aug-cc-pVDZ atomic basis set ${ }^{87,88}$ was systematically applied in combination with the corresponding auxiliary aug-cc-pVDZ-RI basis set for the two latter methods, a choice that is justified by the trifling variations of the results when larger basis sets are selected (see the supplementary material). TD-DFT transitions were computed using the M06- $2 \mathrm{X}^{84}$ functional that contains an exact exchange percentage of 54\%. TD-DFT calculations have been performed with Gaussian $09^{83}$ in both gas phase and solution using both the LR and the corrected LR (cLR) ${ }^{89}$ $\mathrm{PCM}^{13}$ scheme considering the non-equilibrium (neq) limit. The ADC(2) calculations were performed with the Turbomole code, ${ }^{90}$ applying the so-called $\mathrm{ADC}(2)$-s formalism ${ }^{40}$ and relying on the resolution-of-the-identity (RI) technique. ${ }^{91,92}$ The $G W$ and BSE calculations have been performed with the Fiesta package, ${ }^{63,93,94}$ a Gaussian-basis implementation of the $G W$ and BSE formalisms using the Coulomb-fitting (RI-V) approach. ${ }^{95}$ The input DFT eigenstates were generated with the NWChem package, ${ }^{96}$ using the M06-2X functional ${ }^{84}$ except when noted explicitly. The NWChem calculations rely on the $x$ fine integration grid with total energies and densities converged to $10^{-7}$ and $10^{-6}$ a.u., respectively. We used a partially self-consistent $G W$ approach, denoted as evGW in the following. It consists in converging the $G W$ equations by re-injecting the eigenvalues until self-consistency is reached, the DFT eigenfunctions being frozen. The evGW scheme avoids any significant XCF dependency. This statement was confirmed using one cationic dye (Table S2 in the supplementary material): the BSE/evGW @M06-2X transition energies are very similar to those obtained with other XCF of the M06 family. Since the computational cost of calculating the $G W$ correction rises with the number of corrected eigenvalues, we corrected explicitly a finite number of states around the gap, rigidly shifting the other states to preserve the DFT energy spacing with the lowest/highest ev $G W$-corrected energy levels. We typically chose to correct the same number of occupied valence states and of virtual states, and test calculations revealed that correcting 5 occupied and 5 virtual levels was suited for our purposes (see Table S3 in the supplementary material). Comparisons between BSE and TD-DFT computational costs can be found elsewhere. ${ }^{97}$ In practice, the computational cost of $\mathrm{BSE} / \mathrm{ev} G W$ is mostly due to the $G W$ step and the total computational cost of BSE/ev $G W$ is in between the ones of TD-DFT and $\operatorname{ADC}(2)$. We recall here that the BSE/ev $G W$ computational cost scales as $\mathcal{O}\left(N^{4}\right)$ that can be compared to $\mathcal{O}\left(N^{5}\right)$ for $\operatorname{ADC}(2)$.

\section{RESULTS AND DISCUSSION}

\section{A. 0-0 energies}

We start by comparing experimental and theoretical $0-0$ energies, as such comparison allows a well-grounded assessment of the theoretical approaches. ${ }^{98-100}$ However, besides the fact that 0-0 theoretical energies require a large computational effort (the ES Hessian needs to be determined), one can only perform such comparisons for dyes for which the emission spectrum has been measured, as the experimental $0-0$ reference energy is the absorption-fluorescence crossing point. ${ }^{98-100}$ We have gathered a set of five cationic compounds with available experimental values in Table I that also lists the theoretical 0-0 energies obtained following a protocol detailed elsewhere. ${ }^{43}$ A comparison between experimental and theoretical values can be found in Figure 2. Clearly, irrespective of the selected environmental model, TD-DFT provides too large $0-0$ energies, in line with previous works. ${ }^{34,35}$ Both $\mathrm{ADC}(2)$ and $\mathrm{BSE} / \mathrm{ev} G W$ yield much more accurate results, the former method being the most accurate when neglecting solvent effects (left panel of Figure 2) or when using the cLR-PCM scheme (right panel), while the latter approach is the closest from the spot in combination with LR-PCM (central panel). In these three "optimal" cases, i.e., gas/ADC(2), LR-PCM/BSE/ev $G W$, and cLR-PCM/ADC(2), the obtained MAD is smaller than $0.1 \mathrm{eV}$, which is certainly an excellent result. Interestingly, irrespective of the selected model, $\mathrm{BSE} / \mathrm{ev} G W$ systematically delivers the largest correlation with experiment, e.g., $R=0.994$ with cLR-PCM. As this stage, we recall that cLR-PCM relies on the change of total dipole moment upon transition and is therefore adequate for chargetransfer cases, whereas LR-PCM relies on the transition dipole moment and consequently includes dispersion-like effects that can dominate the response for local ES; the interested reader will find more throughout the discussions about the differences of these approaches elsewhere. ${ }^{101-103}$ As the dyes considered here are between these two extreme cases, no univocal choice of the "best" solvent model can be made and we have therefore continued our study with both models.

\section{B. Vertical transitions and auxochromic effects}

In this Section, we compare the lowest excitation energies obtained for 26 dyes with the three selected levels of theory. The main results, obtained within the vertical approximation, are listed in Table II. As can be seen, many compounds show two strong absorption bands so that a statistically significant

TABLE I. Comparison between experimental and theoretical 0-0 energies for five compounds. TD, ADC, and BSE stand for TD-M06-2X, ADC(2), and BSE/evGW@M06-2X, respectively. All values are in eV and rely on the aug-cc-pVDZ atomic basis set (see main text).

\begin{tabular}{|c|c|c|c|c|c|c|c|c|c|c|c|c|}
\hline \multicolumn{4}{|c|}{ Experiment } & \multicolumn{3}{|c|}{ Gas } & \multicolumn{3}{|c|}{ LR-PCM } & \multicolumn{3}{|c|}{ cLR-PCM } \\
\hline Dye & Solvent & $\Delta E$ & References & $\mathrm{TD}$ & $\mathrm{ADC}$ & BSE & $\mathrm{TD}$ & $\mathrm{ADC}$ & BSE & $\mathrm{TD}$ & $\mathrm{ADC}$ & BSE \\
\hline MHB, $\mathrm{R}=\mathrm{H}$ & Water & 2.02 & 104 & 2.60 & 1.93 & 2.34 & 2.14 & 1.47 & 1.87 & 2.59 & 1.92 & 2.32 \\
\hline $\mathrm{MHB}, \mathrm{R}=\mathrm{NH}_{2}$ & Water & 2.71 & 105 and 106 & 3.06 & 2.43 & 2.84 & 2.81 & 2.17 & 2.59 & 3.08 & 2.45 & 2.86 \\
\hline ACRC, $X, X^{\prime}=N, S, R, R^{\prime}=M e$ & Water & 1.82 & 105 & 2.49 & 1.87 & 2.18 & 2.05 & 1.43 & 1.74 & 2.43 & 1.80 & 2.11 \\
\hline ACRC, $X, X^{\prime}=N, O, R, R^{\prime}=E t$ & $\mathrm{MeOH}$ & 1.90 & 9 & 2.56 & 1.90 & 2.25 & 2.09 & 1.43 & 1.78 & 2.50 & 1.84 & 2.19 \\
\hline ACRC, $\mathrm{X}, \mathrm{X}^{\prime}=\mathrm{CH}, \mathrm{N}, \mathrm{R}, \mathrm{R}^{\prime}=\mathrm{Me}$ & Water & 2.40 & 105 & 2.96 & 2.38 & 2.70 & 2.66 & 2.08 & 2.40 & 2.93 & 2.35 & 2.68 \\
\hline
\end{tabular}



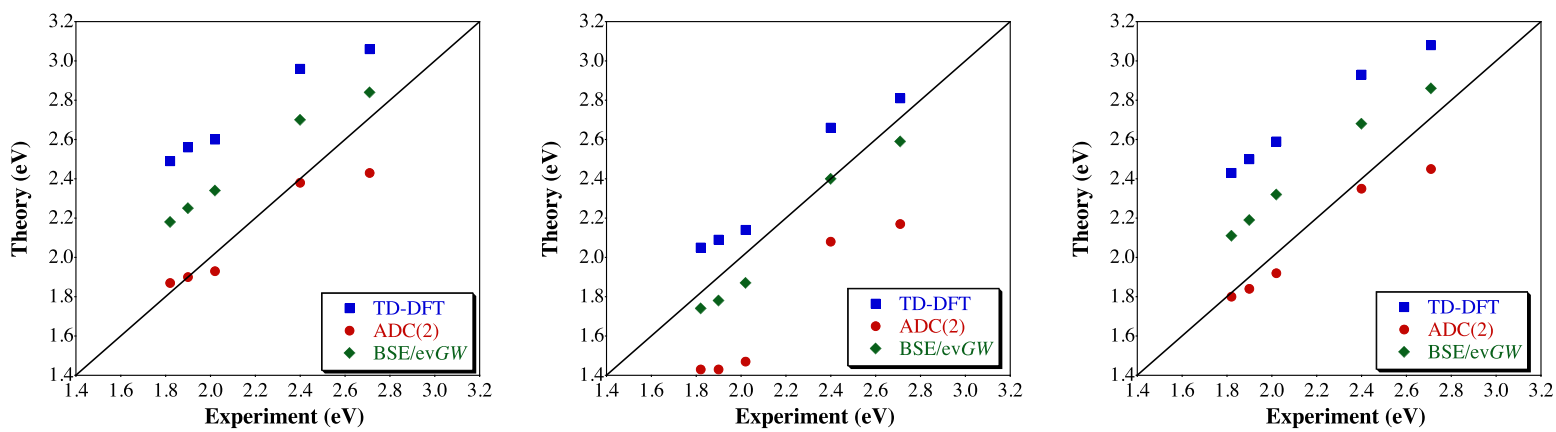

FIG. 2. Comparison between experimental (solution) and theoretical 0-0 energies for the data listed of Table I. From left to right, theoretical values obtained in gas phase, with LR-PCM and cLR-PCM results. The central line indicates a perfect theory/experiment match. All values are in $\mathrm{eV}$.

TABLE II. Vertical transition energies corresponding to the main $\pi \rightarrow \pi^{\star}$ transitions of arylcarbonium dyes. AC stands for acetic acid and CHL for chloroform. See caption of Table I.

\begin{tabular}{|c|c|c|c|c|c|c|c|c|c|c|}
\hline \multicolumn{3}{|c|}{ Dye } & \multicolumn{2}{|r|}{ Expt. } & \multicolumn{3}{|c|}{ LR-PCM } & \multicolumn{3}{|c|}{ cLR-PCM } \\
\hline Series & Subst. & Solvent & $\lambda_{\max }$ & References & TD & ADC & BSE & $\mathrm{TD}$ & $\mathrm{ADC}$ & BSE \\
\hline \multirow[t]{19}{*}{ MG } & None & $\mathrm{AC}$ & 2.00 & $107-113$ & 2.502 & 1.806 & 2.273 & 2.619 & 1.923 & 2.391 \\
\hline & & & 2.90 & & 3.426 & 2.843 & 3.245 & 3.488 & 2.904 & 3.307 \\
\hline & 2,6-Me & $\mathrm{AC}$ & 1.99 & 108,111 , and 114 & 2.476 & 1.753 & 2.232 & 2.612 & 1.889 & 2.367 \\
\hline & & & 3.02 & & 3.424 & 3.096 & 3.382 & 3.295 & 2.966 & 3.253 \\
\hline & $4-\mathrm{Cl}$ & $\mathrm{AC}$ & 1.98 & 113 and 114 & 2.483 & 1.783 & 2.250 & 2.602 & 1.902 & 2.369 \\
\hline & & & 2.86 & & 3.370 & 2.837 & 3.205 & 3.415 & 2.882 & 3.250 \\
\hline & $4-\mathrm{CF}_{3}$ & $\mathrm{AC}$ & 1.95 & 110 and 111 & 2.449 & 1.749 & 2.213 & 2.573 & 1.873 & 2.337 \\
\hline & & & 2.92 & & 3.526 & 2.911 & 3.329 & 3.592 & 2.977 & 3.395 \\
\hline & $4-\mathrm{CN}$ & $\mathrm{AC}$ & 1.93 & 110 & 2.416 & 1.718 & 2.188 & 2.535 & 1.838 & 2.307 \\
\hline & & & 2.89 & & 3.475 & 2.905 & 3.305 & 3.545 & 2.974 & 3.375 \\
\hline & 4-Me & $\mathrm{AC}$ & 2.01 & $107-109,111$, and 114 & 2.522 & 1.826 & 2.283 & 2.635 & 1.939 & 2.396 \\
\hline & & & 2.83 & & 3.305 & 2.762 & 3.134 & 3.350 & 2.807 & 3.179 \\
\hline & $4-\mathrm{NMe}_{2}$ & Water & 2.10 & 106 & 2.657 & 1.982 & 2.433 & 2.721 & 2.047 & 2.498 \\
\hline & $4-\mathrm{NO}_{2}$ & $\mathrm{AC}$ & 1.92 & $109,110,113$, and 114 & 2.388 & 1.694 & 2.175 & 2.500 & 1.806 & 2.287 \\
\hline & & & 2.92 & & 3.492 & 2.881 & 3.313 & 3.561 & 2.950 & 3.382 \\
\hline & $4-\mathrm{OH}$ & $\mathrm{AC}$ & 2.06 & 114 & 2.552 & 1.858 & 2.320 & 2.656 & 1.961 & 2.423 \\
\hline & & & 2.64 & & 3.139 & 2.576 & 2.938 & 3.180 & 2.617 & 2.980 \\
\hline & 4-OMe & $\mathrm{AC}$ & 2.04 & 107 and 114 & 2.558 & 1.867 & 2.327 & 2.661 & 1.971 & 2.431 \\
\hline & & & 2.67 & & 3.097 & 2.516 & 2.901 & 3.126 & 2.545 & 2.930 \\
\hline \multirow[t]{5}{*}{ TPC } & None & Water/ $\mathrm{H}_{2} \mathrm{SO}_{4}$ & 2.88 & 115 & 3.316 & 2.947 & 3.025 & 3.354 & 2.982 & 3.062 \\
\hline & & & 3.06 & & 3.488 & 3.142 & 3.286 & 3.522 & 3.179 & 3.321 \\
\hline & $4,4^{\prime}, 4^{\prime \prime}-\mathrm{OMe}$ & $\mathrm{CHL}$ & 2.58 & 115 & 3.011 & 2.437 & 2.770 & 3.087 & 2.513 & 2.846 \\
\hline & $4,4^{\prime}-\mathrm{OMe}, 4^{\prime \prime}-\mathrm{NO}_{2}$ & CHL & 2.44 & 115 & 2.777 & 2.156 & 2.548 & 2.891 & 2.270 & 2.661 \\
\hline & & & 2.95 & & 3.598 & 3.175 & 3.433 & 3.658 & 3.236 & 3.493 \\
\hline \multirow[t]{14}{*}{ MHB } & $\mathrm{R}=\mathrm{H}$ & $\mathrm{AC}$ & 2.04 & 108,114 , and $116-118$ & 2.525 & 1.904 & 2.259 & 2.695 & 2.075 & 2.430 \\
\hline & $\mathrm{R}=\mathrm{H}$ and $2-\mathrm{CF}_{3}$ & $\mathrm{AC}$ & 1.99 & 119 & 2.498 & 1.885 & 2.249 & 2.617 & 2.004 & 2.367 \\
\hline & $\mathrm{R}=\mathrm{H}$ and $2,2^{\prime}-\mathrm{CF}_{3}$ & $\mathrm{AC}$ & 1.91 & 119 & 2.375 & 1.736 & 2.118 & 2.520 & 1.881 & 2.263 \\
\hline & $\mathrm{R}=\mathrm{H}$ and 2-Me & $\mathrm{AC}$ & 2.02 & 108 and 116 & 2.497 & 1.873 & 2.238 & 2.655 & 2.031 & 2.396 \\
\hline & $\mathrm{R}=\mathrm{H}$ and $2,2^{\prime}-\mathrm{Me}$ & $\mathrm{AC}$ & 1.99 & 108 and 116 & 2.455 & 1.839 & 2.203 & 2.602 & 1.985 & 2.349 \\
\hline & $\mathrm{R}=\mathrm{CF}_{3}$ & $\mathrm{AC}$ & 1.80 & 118 & 2.319 & 1.644 & 2.062 & 2.475 & 1.800 & 2.219 \\
\hline & $\mathrm{R}=\mathrm{CF}_{3}$ and 2-Me & $\mathrm{AC}$ & 1.81 & 118 & 2.301 & 1.638 & 2.051 & 2.453 & 1.791 & 2.203 \\
\hline & & & 3.42 & & 3.849 & 3.102 & 3.579 & 3.897 & 3.150 & 3.627 \\
\hline & $\mathrm{R}=\mathrm{CF}_{3}$ and $2,2^{\prime}-\mathrm{Me}$ & $\mathrm{AC}$ & 1.92 & 118 & 2.233 & 1.534 & 1.985 & 2.343 & 1.644 & 2.095 \\
\hline & & & 3.50 & & 3.770 & 3.111 & 3.513 & 3.823 & 3.165 & 3.567 \\
\hline & $\mathrm{R}=\mathrm{NH}_{2}$ & Water & 2.88 & 114 and 120 & 3.215 & 2.618 & 3.008 & 3.228 & 2.631 & 3.022 \\
\hline & & & 3.37 & & 3.855 & 3.170 & 3.676 & 3.893 & 3.208 & 3.715 \\
\hline & $\mathrm{R}=t \mathrm{Bu}$ & $\mathrm{AC}$ & 2.03 & 108,114 , and 118 & 2.493 & 1.715 & 2.225 & 2.574 & 1.796 & 2.307 \\
\hline & & & 3.08 & & 3.674 & 2.933 & 3.446 & 3.732 & 2.991 & 3.504 \\
\hline DPC & None & Water/ $\mathrm{H}_{2} \mathrm{SO}_{4}$ & 2.81 & 115 & 3.250 & 2.913 & 2.950 & 3.367 & 3.030 & 3.066 \\
\hline \multirow[t]{2}{*}{$\mathbf{B G}^{\mathrm{a}}$} & None & $\mathrm{MeOH}$ & 1.71 & 121 & 1.996 & 1.645 & 1.809 & 2.136 & 1.785 & 1.948 \\
\hline & $2,2^{\prime}-\mathrm{Cl}$ & $\mathrm{MeOH}$ & 1.67 & 121 & 1.925 & 1.614 & 1.770 & 2.054 & 1.743 & 1.899 \\
\hline
\end{tabular}

${ }^{\mathrm{a}}$ In the calculations, $\mathrm{NMe}_{2}$ rather than $\mathrm{NEt}_{2}$ groups were used. 
set of 41 maxima has been considered. We provide in Table S4, the Pearson correlation matrix for all approaches. As could be expected, all correlations are very large $(R>0.96)$, but the correlation between TD-DFT and BSE/ev $G W$ are especially big $(R>0.99)$, in line with a recent investigation focussed on 0-0 energies. ${ }^{43}$ The correlation between experimental and theoretical results is also very satisfying and very similar with both solvent models, e.g., 0.985 and 0.982 with BSE/ev $G W$ using LR-PCM or cLR-PCM solvent corrections. Figure 3 provides a comparison between experimental and theoretical values for all methods. The trends are very similar to those of Figure 2 with (i) a strong overestimation of the experimental data with TD-M06-2X; (ii) BSE/ev $G W$ values bracketed by the results of the two other methods; (iii) LR transition energies smaller than their cLR counterparts; and (iv) the combination of cLRPCM with ADC(2) leading the smallest deviations. However, as the theoretical estimates neglect vibrational effects, it is probably more sound to compare auxochromic effects than absolute transition energies.

In the MG series, the largest measured hypsochromic (bathochromic) shift is obtained when adding a dimethylamino (nitro) group at position 4 (see Figure 1): $+0.10 \mathrm{eV}$ $(-0.08 \mathrm{eV})$. With the cLR-PCM solvation model, these effects are well reproduced by all theories with variations of $+0.10 \mathrm{eV}$ $(-0.10 \mathrm{eV}),+0.12 \mathrm{eV}(-0.12 \mathrm{eV})$, and $+0.11 \mathrm{eV}(-0.10 \mathrm{eV})$ with TD-DFT, $\mathrm{ADC}(2)$, and $\mathrm{BSE} / \mathrm{ev} G W$, respectively. Using LR-PCM yields very similar auxochromic effects for the 4- $\mathrm{NO}_{2}$ compound, but significantly overestimated variations for the 4-NMe $\mathrm{N}_{2}$ dye (see Table II). Replacing the central hydrogen atom $(\mathrm{R})$ of $\mathbf{M H B}$ by a $\mathrm{CF}_{3}\left(\mathrm{NH}_{2}\right)$ group yields an experimental $\lambda_{\max }$ shift of $-0.24 \mathrm{eV}(+0.84 \mathrm{eV})$. Theory nicely reproduces the impact of the trifluoromethyl moiety with estimated changes of $-0.22 \mathrm{eV},-0.28 \mathrm{eV}$, and $-0.21 \mathrm{eV}$ with TD-DFT, $\mathrm{ADC}(2)$, and $\mathrm{BSE} / \mathrm{ev} G W$, respectively, when applying cLR-PCM and similar values with LR-PCM. In contrast, for the amino group, the LR-PCM estimates of $+0.69 \mathrm{eV}$, $+0.71 \mathrm{eV}$, and $+0.75 \mathrm{eV}$ are significantly more accurate than their cLR-PCM counterparts of $+0.53 \mathrm{eV},+0.56 \mathrm{eV}$, and $+0.59 \mathrm{eV}$, for the same three theoretical models, respectively. For fifteen compounds, two absorption bands have been reported in the experimental works and the separation between these two bands (in the $0.18-1.61 \mathrm{eV}$ range experimentally) is also an important criterion for assessing the quality of the theoretical models. For these separations, the MAD obtained at TD-DFT, $\mathrm{ADC}(2)$, and $\mathrm{BSE} / \mathrm{ev} G W$ levels, respectively, attain $0.08 \mathrm{eV}, 0.16 \mathrm{eV}$, and $0.12 \mathrm{eV}$, with the LR-PCM model and $0.12 \mathrm{eV}, 0.13 \mathrm{eV}$, and $0.11 \mathrm{eV}$ with the cLR-PCM approach. In other words, for this parameter, both TD-DFT and BSE/ev $G W$ are slightly more accurate than $\operatorname{ADC}(2)$, irrespective of the selected environmental model.

A statistical analysis of the results of Table II can be found in Table S5 in the supplementary material. This analysis confirms the above trends: $\mathrm{ADC}(2)$ provides the smallest absolute deviations with respect to the experimental values with a MAD of $0.10 \mathrm{eV}$ for cLR-PCM/ADC(2), but the two other approaches deliver larger correlation of the experimental values, at the cost of an overestimation of the transition energies that is large (ca. $0.50 \mathrm{eV}$ ) with TD-M06-2X. In short, all approaches reproduce auxochromic effects, $\mathrm{BSE} / \mathrm{ev} G W$ and TD-DFT being slightly better for these shifts.

\section{Acidochromic effects}

In this Section, we compare the lowest excitation energies obtained for a series of ACRC derivatives, as many compounds of this group have been investigated under different protonation states (see Table III). Reproducing the acidochromic effects, i.e., the change of color following variations of the $\mathrm{pH}$, is clearly a major challenge as the nature of the relevant ES can be significantly modified with the protonation state, e.g., it can go from a cyanine to a local or charge-transfer state. First, we underline that considering the singly positively charged species only (12 compounds), we obtain similar statistical values as in Sec. III B. For instance, the cLR-PCM MAD is $0.63 \mathrm{eV}, 0.12 \mathrm{eV}$, and $0.34 \mathrm{eV}$ with TD-DFT, $\mathrm{ADC}(2)$, and $\mathrm{BSE} / \mathrm{ev} G W$, respectively, and these figures are close to the $0.56 \mathrm{eV}, 0.10 \mathrm{eV}$, and $0.34 \mathrm{eV}$ average deviations listed in Table S-V. For methylene blue (top compound in Table III), the protonation induces a large redshift of the main absorption band $(-0.20 \mathrm{eV})$. All theoretical models correctly reproduce the sign of this variation but with significantly different amplitudes. Indeed, $\mathrm{ADC}(2)$ underrates this change $(-0.12 \mathrm{eV}$ and $-0.10 \mathrm{eV}$ with LR-PCM and CLR-PCM), whereas both TD-DFT $(-0.36 \mathrm{eV}$ and $-0.34 \mathrm{eV})$ and BSE/ev $G W(-0.40 \mathrm{eV}$ and $-0.38 \mathrm{eV}$ ) suffer from the opposite error. For the acridine derivative $\left(X, X^{\prime}=C H, N, R, R^{\prime}=M e, M e\right.$ in Table III), starting from the monocationic structure and going to the neutral and dicationic forms induce variations of the $\lambda_{\max }$ of $+0.32 \mathrm{eV}$ and $-0.05 \mathrm{eV}$, respectively, according to the measurements. The cLR-PCM theoretical estimates are $+0.29 \mathrm{eV}$ and $-0.14 \mathrm{eV}$ with TD-DFT, $+0.47 \mathrm{eV}$ and $-0.11 \mathrm{eV}$ with $\mathrm{ADC}(2)$, and $+0.26 \mathrm{eV}$ and $-0.12 \mathrm{eV}$ using BSE/ev $G W$, respectively. In other words, the sign of the change is systematically correct, but $\mathrm{ADC}(2)$ overestimates significantly the magnitude of the difference between
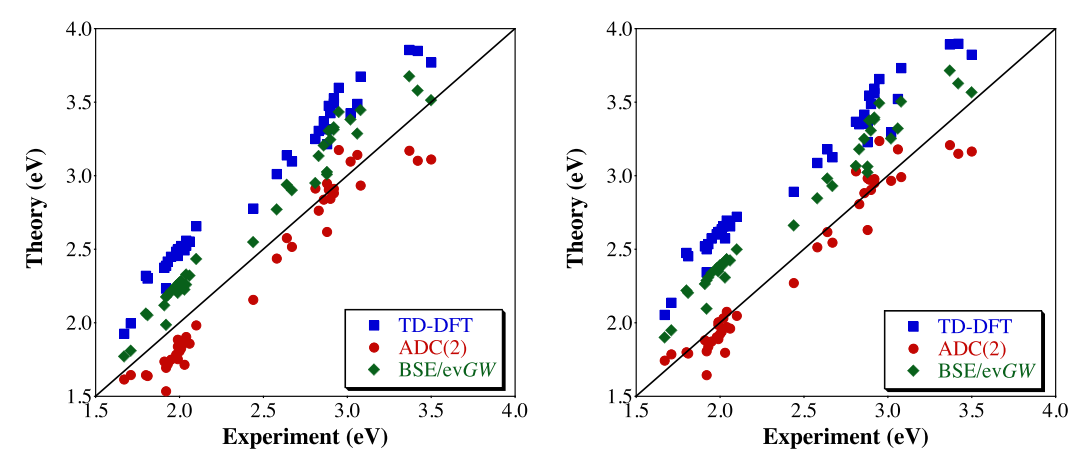

FIG. 3. Comparison between experimental $\left(\lambda_{\max }\right)$ and theoretical (vertical) transition energies for the ES listed in Table II. Left: LR-PCM; right: cLR-PCM results. The central line indicates a perfect theory/experiment match. All values are in $\mathrm{eV}$. 
TABLE III. Vertical transition energies corresponding to the main $\pi \rightarrow \pi^{\star}$ transitions in ACRC derivatives in eV. $Q$ is the total charge of the dye, indicating its protonation state.

\begin{tabular}{|c|c|c|c|c|c|c|c|c|c|c|c|c|}
\hline \multicolumn{5}{|c|}{ Dye } & \multicolumn{2}{|r|}{ Expt. } & \multicolumn{3}{|c|}{ LR-PCM } & \multicolumn{3}{|c|}{ cLR-PCM } \\
\hline$X, X^{\prime}$ & $\mathrm{R}, \mathrm{R}^{\prime}$ & Subst. & $Q$ & Solvent & $\lambda_{\max }$ & References & TD-DFT & $\operatorname{ADC}(2)$ & $\mathrm{BSE} / G W$ & TD-DFT & $\operatorname{ADC}(2)$ & $\mathrm{BSE} / G W$ \\
\hline \multirow[t]{2}{*}{$\mathrm{N}, \mathrm{S}$} & $\mathrm{Me}, \mathrm{Me}$ & & +1 & Water & 1.87 & 8 and 122 & 2.422 & 1.874 & 2.112 & 2.532 & 1.984 & 2.222 \\
\hline & & & +2 & Water & 1.67 & 8 & 2.058 & 1.751 & 1.712 & 2.191 & 1.884 & 1.846 \\
\hline \multirow[t]{4}{*}{$\mathrm{N}, \mathrm{S}$} & $\mathrm{H}, \mathrm{H}$ & & 0 & Water & 2.41 & 7 & 2.856 & 2.709 & 2.643 & 2.899 & 2.753 & 2.687 \\
\hline & & & +1 & Water & 2.08 & 7 and 123 & 2.649 & 2.221 & 2.296 & 2.764 & 2.336 & 2.410 \\
\hline & & & +2 & Water & 1.84 & 7 & 2.290 & 2.113 & 1.902 & 2.389 & 2.211 & 2.000 \\
\hline & & & +3 & Water & 1.84 & 7 & 2.135 & 1.715 & 1.858 & 2.133 & 1.714 & 1.857 \\
\hline $\mathrm{N}, \mathrm{N}-\mathrm{H}$ & $\mathrm{Me}, \mathrm{H}$ & 3-Me & +1 & Water & 2.35 & 124 & 2.796 & 2.307 & 2.495 & 2.852 & 2.363 & 2.551 \\
\hline \multirow[t]{3}{*}{$\mathrm{CH}, \mathrm{N}$} & $\mathrm{Me}, \mathrm{Me}$ & & 0 & Water & 2.85 & 9 & 3.353 & 3.015 & 3.068 & 3.368 & 3.029 & 3.083 \\
\hline & & & +1 & Water & 2.53 & 9 and 125 & 3.018 & 2.493 & 2.760 & 3.081 & 2.556 & 2.823 \\
\hline & & & +2 & Water & 2.48 & 115 & 2.982 & 2.486 & 2.743 & 2.939 & 2.443 & 2.699 \\
\hline $\mathrm{N}, \mathrm{N}-\mathrm{Ph}$ & $\mathrm{H}, \mathrm{H}$ & 3,6-Me & +1 & Water & 2.36 & 125 & 2.918 & 2.550 & 2.625 & 3.013 & 2.645 & 2.719 \\
\hline $\mathrm{C}-\mathrm{H}, \mathrm{O}$ & $\mathrm{Me}, \mathrm{Me}$ & & +1 & EtOH & 2.25 & 126 & 2.804 & 2.230 & 2.548 & 2.911 & 2.337 & 2.655 \\
\hline $\mathrm{C}-\mathrm{CN}, \mathrm{O}$ & $\mathrm{Me}, \mathrm{Me}$ & & +1 & $\mathrm{EtOH}$ & 1.90 & 126 & 2.433 & 1.865 & 2.183 & 2.534 & 1.965 & 2.284 \\
\hline $\mathrm{C}-\mathrm{CF}_{3}, \mathrm{O}$ & $\mathrm{Me}, \mathrm{Me}$ & & +1 & $\mathrm{EtOH}$ & 2.01 & 126 & 2.581 & 1.973 & 2.333 & 2.694 & 2.086 & 2.446 \\
\hline $\mathrm{S}, \mathrm{CH}$ & $\mathrm{Me}, \mathrm{Me}$ & & +1 & $\mathrm{EtOH}$ & 2.21 & 126 & 2.721 & 2.132 & 2.447 & 2.812 & 2.223 & 2.538 \\
\hline \multirow[t]{2}{*}{$\mathrm{N}, \mathrm{S}$} & $\mathrm{Me}, \mathrm{Me}^{\mathrm{a}}$ & & 0 & Water & 2.00 & 6 & 2.643 & 2.451 & 2.444 & 2.676 & 2.485 & 2.477 \\
\hline & & & +1 & Water & 1.91 & 6 & 2.470 & 1.949 & 2.147 & 2.585 & 2.063 & 2.262 \\
\hline \multirow[t]{3}{*}{$\mathrm{CH}, \mathrm{N}$} & $\mathrm{H}, \mathrm{H}$ & & 0 & Water & 3.14 & 115 and 127 & 3.639 & 3.426 & 3.325 & 3.660 & 3.448 & 3.346 \\
\hline & & & +1 & Water & 2.79 & 106,115 , and 127 & 3.263 & 2.870 & 2.984 & 3.337 & 2.944 & 3.057 \\
\hline & & & +2 & Water & 2.76 & 115 & 3.178 & 2.803 & 2.918 & 3.138 & 2.763 & 2.878 \\
\hline $\mathrm{N}, \mathrm{O}$ & $\mathrm{Et}, \mathrm{Et}^{\mathrm{b}}$ & & +1 & Water & 1.90 & 122 & 2.486 & 1.929 & 2.182 & 2.617 & 2.060 & 2.313 \\
\hline
\end{tabular}

${ }^{\mathrm{a}}$ The donating group is NMe in the neutral form and NHMe in the cationic form.

${ }^{\mathrm{b}}$ In the calculations, $\mathrm{NMe}_{2}$ rather than $\mathrm{NEt}_{2}$ groups were used.

the monocationic and neutral forms. The results are rather similar for proflavine $\left(X, X^{\prime}=\mathrm{CH}, \mathrm{N}, \mathrm{R}, \mathrm{R}^{\prime}=\mathrm{H}, \mathrm{H}\right.$ in Table III): the difference between the mono- and dicationic forms is well restored by TD-DFT and BSE/ev $G W$ and overestimated with $\operatorname{ADC}(2)$, whereas the shift when going to the neutral species is always overshot by all theories, especially when using the cLR-PCM model. Overall, from Table III, one can extract nine linearly independent acidochromic shifts and, using the monocation case as reference in each case, we determined MAD of $0.10 \mathrm{eV}(0.13 \mathrm{eV}), 0.17 \mathrm{eV}(0.17 \mathrm{eV})$, and $0.10 \mathrm{eV}(0.13 \mathrm{eV})$ for TD-DFT, $\mathrm{ADC}(2)$, and $\mathrm{BSE} / \mathrm{ev} G W$, respectively, using the LR-PCM (cLR-PCM) environmental model. In all cases, all theories reproduce the correct sign of the acidochromic effect.

\section{CONCLUSIONS AND OUTLOOK}

In an effort to extend the palette of applications of ES calculations, we have investigated more than sixty electronic transitions in a large panel of carbocationic dyes known to be especially challenging for theoretical approaches. We have applied three levels of theory: (i) TD-DFT in combination with the M06-2X functional; (ii) $\mathrm{ADC}(2)$ that remains a relatively affordable wavefunction approach despite its formal $\mathcal{O}\left(N^{5}\right)$ scaling with system size; and (iii) BSE relying on a partially self-consistent $G W$ approach allowing to obtain transition energies almost independent of the starting eigenstates while conserving the same $\mathcal{O}\left(N^{4}\right)$ scaling as TD-DFT. We have also considered two solvation models: the linearresponse PCM approach and the state-specific corrected linearresponse PCM scheme. It appeared that $\mathrm{BSE} / G W$ transition energies are almost systematically more accurate than their TD-DFT counterparts that are significantly too large. Indeed, the TD-M06-2X overestimations are of the order of $0.5 \mathrm{eV}$, an usually large error related to the specific nature of these dyes. ADC(2) provides smaller deviations with respect to the experiment in the vast majority of cases. In terms of correlation with respect to experiment, BSE/ev $G W$ outperforms $\operatorname{ADC}(2)$ and this holds for auxochromic shifts, separation between the two main absorption bands and acidochromic effects. The selection of the LR or cLR PCM models has a small impact on these correlations but significantly tunes the absolute transition energies: the former model leads to larger solvatochromic effects and hence smaller transition energies. This might have an important effect on the obtained conclusions, e.g., for the 0-0 energies that allow the most significant comparisons between simulated and measured spectra, $\mathrm{BSE} / \mathrm{ev} G W$ is the most accurate approach when using LR-PCM solvent corrections, whereas ADC(2) occupies the top spot when cLR-PCM corrections are applied. In short, we can recommend the use of the LR-PCM-BSE/ev $G W$ method to model the excited-states of arylcarbonium dyes because it delivers the most valuable accuracy/time ratio of the tested approaches.

We are continuing our efforts to assess the performances of the BSE/GW theory, especially for the molecules or states for which TD-DFT is experiencing limitations. As the present work also demonstrates that the solvation effects going beyond the linear-response regime are essential, the coupling of BSE with such state-specific approach is also one of our short-term objective, following the recent 
merging of the $G W$ formalism with continuous ${ }^{128}$ and discrete $^{129}$ polarizable models.

\section{SUPPLEMENTARY MATERIAL}

See supplementary material for methodological investigation of (i) basis set effects; (ii) impact of the selected functional on the BSE results; (iii) impact of the number of corrected levels at the $G W$ level. Complementary statistical analysis for the data of Table II.

\section{ACKNOWLEDGMENTS}

C.A. acknowledges the support of the Agence Nationale de La Recherche (ANR - EMA grant) for her Ph.D. Grant. D.J. acknowledges the European Research Council for financial support in the framework of Starting Grant (No. Marches 278845). The authors thank the Région des Pays de la Loire for the LUMOMAT RFI Project. This work was performed using resources of the GENCI-CINES/IDRIS, of the CCIPL (Centre de Calcul Intensif des Pays de la Loire), and of a local Troy cluster.

${ }^{1}$ I. K. Kandela, J. A. Bartlett, and G. L. Indig, Photochem. Photobiol. Sci. 1, 309 (2002).

${ }^{2}$ A. Basu and G. S. Kumar, J. Chem. Thermodyn. 98, 208 (2016).

${ }^{3}$ M. Quadir, "Cosmetic composition for keratinous substrates with triarylmethane compounds," U.S. patent 7,416,567 (28 August 2008).

${ }^{4}$ S. Liu, Z. Zhang, Q. Liu, H. Luo, and W. Zheng, J. Pharm. Biomed. Anal. 30, 685 (2002).

${ }^{5}$ A. K. Jana, J. Photochem. Photobiol., A 132, 1 (2000).

${ }^{6}$ G. S. Singhal and E. Rabinowitch, J. Phys. Chem. 71, 3347 (1967).

${ }^{7}$ L. F. Epstein, F. Karush, and E. Rabinowitch, J. Opt. Soc. Am. 31, 77 (1941).

${ }^{8}$ J. Cenens and R. A. Schoonheydt, Clays Clay Miner. 36, 214 (1988).

${ }^{9}$ M. Shaikh, J. Mohanty, P. K. Singh, W. M. Nau, and H. Pal, Photochem. Photobiol. Sci. 7, 408 (2008).

${ }^{10}$ E. Runge and E. K. U. Gross, Phys. Rev. Lett. 52, 997 (1984).

${ }^{11}$ M. E. Casida, "Time-dependent density-functional theory response theory for molecules," in Recent Advances in Density Functional Methods, edited by D. P. Chong (World Scientific, Singapore, 1995), Vol. 1, pp. 155-192.

${ }^{12}$ M. E. Casida and M. Huix-Rotllant, Annu. Rev. Phys. Chem. 63, 287 (2012).

${ }^{13}$ J. Tomasi, B. Mennucci, and R. Cammi, Chem. Rev. 105, 2999 (2005).

${ }^{14}$ A. D. Laurent, C. Adamo, and D. Jacquemin, Phys. Chem. Chem. Phys. 16, 14334 (2014).

${ }^{15}$ F. Furche and R. Ahlrichs, J. Chem. Phys. 117, 7433 (2002).

${ }^{16}$ C. V. Caillie and R. D. Amos, Chem. Phys. Lett. 308, 249 (1999).

${ }^{17}$ G. Scalmani, M. J. Frisch, B. Mennucci, J. Tomasi, R. Cammi, and V. Barone, J. Chem. Phys. 124, 094107 (2006).

${ }^{18}$ J. Liu and W. Liang, J. Chem. Phys. 135, 184111 (2011).

${ }^{19}$ V. Barone, J. Bloino, S. Monti, A. Pedone, and G. Prampolini, Phys. Chem. Chem. Phys. 13, 2160 (2011).

${ }^{20}$ D. Jacquemin and C. Adamo, "Computational molecular electronic spectroscopy with TD-DFT," in Density-Functional Methods for Excited States, edited by N. Ferré, M. Filatov, and M. Huix-Rotllant (Springer International Publishing, Cham, 2016), Vol. 368, pp. 347-375.

${ }^{21} \mathrm{~F}$. Santoro and D. Jacquemin, Wiley Interdiscip. Rev.: Comput. Mol. Sci. 6, 460 (2016).

${ }^{22}$ A. D. Laurent and D. Jacquemin, Int. J. Quantum Chem. 113, 2019 (2013).

${ }^{23}$ B. Champagne, M. Guillaume, and F. Zutterman, Chem. Phys. Lett. 425, 105 (2006).

${ }^{24}$ D. Jacquemin, E. A. Perpète, G. Scalmani, M. J. Frisch, R. Kobayashi, and C. Adamo, J. Chem. Phys. 126, 144105 (2007).

${ }^{25}$ S. Grimme and F. Neese, J. Chem. Phys. 127, 154116 (2007).

${ }^{26}$ M. Schreiber, V. Buß, and M. P. Fulscher, Phys. Chem. Chem. Phys. 3, 3906 (2001).

${ }^{27}$ J. Fabian, Theor. Chem. Acc. 106, 199 (2001).

${ }^{28}$ B. Moore II and J. Autschbach, J. Chem. Theory Comput. 9, 4991 (2013).

${ }^{29}$ M. Filatov and M. Huix-Rotllant, J. Chem. Phys. 141, 024112 (2014).
${ }^{30}$ H. Zhekova, M. Krykunov, J. Autschbach, and T. Ziegler, J. Chem. Theory Comput. 10, 3299 (2014).

${ }^{31}$ P. Boulanger, D. Jacquemin, I. Duchemin, and X. Blase, J. Chem. Theory Comput. 10, 1212 (2014).

${ }^{32}$ P. Boulanger, S. Chibani, B. Le Guennic, I. Duchemin, X. Blase, and D. Jacquemin, J. Chem. Theory Comput. 10, 4548 (2014).

${ }^{33}$ B. Le Guennic and D. Jacquemin, Acc. Chem. Res. 48, 530 (2015).

${ }^{34}$ J. Preat, D. Jacquemin, V. Wathelet, J.-M. André, and E. A. Perpète, Chem. Phys. 335, 177 (2007).

${ }^{35}$ D. Jacquemin, V. Wathelet, E. A. Perpète, and C. Adamo, J. Chem. Theory Comput. 5, 2420 (2009).

${ }^{36}$ T. Yanai, D. P. Tew, and N. C. Handy, Chem. Phys. Lett. 393, 51 (2004).

${ }^{37}$ R. Send, O. Valsson, and C. Filippi, J. Chem. Theory Comput. 7, 444 (2011).

${ }^{38}$ M. R. Momeni and A. Brown, J. Chem. Theory Comput. 11, 2619 (2015).

${ }^{39}$ J. Schirmer and A. B. Trofimov, J. Chem. Phys. 120, 11449 (2004).

${ }^{40}$ A. Dreuw and M. Wormit, Wiley Interdiscip. Rev.: Comput. Mol. Sci. 5, 82 (2015).

${ }^{41}$ N. O. C. Winter, N. K. Graf, S. Leutwyler, and C. Hattig, Phys. Chem. Chem. Phys. 15, 6623 (2013).

${ }^{42}$ P. H. P. Harbach, M. Wormit, and A. Dreuw, J. Chem. Phys. 141, 064113 (2014).

${ }^{43}$ D. Jacquemin, I. Duchemin, and X. Blase, J. Chem. Theory Comput. 11, 5340 (2015).

${ }^{44}$ T. Schwabe, K. Sneskov, J. M. H. Olsen, J. Kongsted, O. Christiansen, and C. Hättig, J. Chem. Theory Comput. 8, 3274 (2012).

${ }^{45}$ S. Höfener, J. Comput. Chem. 35, 1716 (2014).

${ }^{46}$ J.-M. Mewes, Z.-Q. You, M. Wormit, T. Kriesche, J. M. Herbert, and A. Dreuw, J. Phys. Chem. A 119, 5446 (2015).

${ }^{47}$ L. J. Sham and T. M. Rice, Phys. Rev. 144, 708 (1966).

${ }^{48}$ W. Hanke and L. J. Sham, Phys. Rev. Lett. 43, 387 (1979).

${ }^{49}$ G. Strinati, Phys. Rev. Lett. 49, 1519 (1982).

${ }^{50}$ L. Hedin, Phys. Rev 139, A796 (1965).

${ }^{51}$ G. Strinati, H. J. Mattausch, and W. Hanke, Phys. Rev. B 25, 2867 (1982).

${ }^{52}$ M. S. Hybertsen and S. G. Louie, Phys. Rev. B 34, 5390 (1986).

${ }^{53}$ D. Jacquemin, I. Duchemin, and X. Blase, J. Chem. Theory Comput. 11, 3290 (2015).

${ }^{54}$ D. Jacquemin, I. Duchemin, and X. Blase, Mol. Phys. 114, 957 (2016).

${ }^{55}$ M. L. Tiago and J. R. Chelikowsky, Solid State Commun. 136, 333 (2005).

${ }^{56}$ M. L. Tiago, P. R. C. Kent, R. Q. Hood, and F. A. Reboredo, J. Chem. Phys. 129, 084311 (2008).

${ }^{57}$ M. Palummo, C. Hogan, F. Sottile, P. Bagalá, and A. Rubio, J. Chem. Phys. 131, 084102 (2009).

${ }^{58}$ Y. Ma, M. Rohlfing, and C. Molteni, Phys. Rev. B 80, 241405 (2009).

${ }^{59}$ M. S. Kaczmarski, Y. Ma, and M. Rohlfing, Phys. Rev. B 81, 115433 (2010).

${ }^{60}$ Y. Ma, M. Rohlfing, and C. Molteni, J. Chem. Theory Comput. 6, 257 (2010).

${ }^{61}$ D. Rocca, D. Lu, and G. Galli, J. Chem. Phys. 133, 164109 (2010).

${ }^{62}$ D. Foerster, P. Koval, and D. Sánchez-Portal, J. Chem. Phys. 135, 074105 (2011).

${ }^{63}$ X. Blase and C. Attaccalite, Appl. Phys. Lett. 99, 171909 (2011).

${ }^{64}$ J. M. Garcia-Lastra and K. S. Thygesen, Phys. Rev. Lett. 106, 187402 (2011).

${ }^{65}$ B. Baumeier, D. Andrienko, Y. Ma, and M. Rohlfing, J. Chem. Theory Comput. 8, 997 (2012).

${ }^{66}$ I. Duchemin, T. Deutsch, and X. Blase, Phys. Rev. Lett. 109, 167801 (2012).

${ }^{67}$ C. Faber, I. Duchemin, T. Deutsch, and X. Blase, Phys. Rev. B 86, 155315 (2012).

${ }^{68}$ I. Duchemin and X. Blase, Phys. Rev. B 87, 245412 (2013).

${ }^{69}$ C. Hogan, M. Palummo, J. Gierschner, and A. Rubio, J. Chem. Phys. 138, 024312 (2013).

${ }^{70}$ B. Baumeier, M. Rohlfing, and D. Andrienko, J. Chem. Theory Comput. 10, 3104 (2014).

${ }^{71}$ D. Varsano, E. Coccia, O. Pulci, A. M. Conte, and L. Guidoni, Comput. Theor. Chem. 1040-1041, 338 (2014).

${ }^{72}$ E. Coccia, D. Varsano, and L. Guidoni, J. Chem. Theory Comput. 10, 501 (2014).

${ }^{73}$ P. Koval, D. Foerster, and D. Sánchez-Portal, Phys. Rev. B 89, 155417 (2014).

${ }^{74}$ S. Körbel, P. Boulanger, I. Duchemin, X. Blase, M. A. L. Marques, and S. Botti, J. Chem. Theory Comput. 10, 3934 (2014).

${ }^{75}$ K. Krause, M. E. Harding, and W. Klopper, Mol. Phys. 113, 1952 (2015).

${ }^{76}$ D. Hirose, Y. Noguchi, and O. Sugino, Phys. Rev. B 91, 205111 (2015).

${ }^{77}$ F. Bruneval, S. M. Hamed, and J. B. Neaton, J. Chem. Phys. 142, 244101 (2015). 
${ }^{78}$ M. P. Ljungberg, P. Koval, F. Ferrari, D. Foerster, and D. Sánchez-Portal, Phys. Rev. B 92, 075422 (2015).

${ }^{79}$ T. Hahn, J. Geiger, X. Blase, I. Duchemin, D. Niedzialek, S. Tscheuschner, D. Beljonne, H. Bässler, and A. Köhler, Adv. Funct. Mater. 25, 1287 (2015).

${ }^{80}$ X. Blase, P. Boulanger, F. Bruneval, M. Fernandez-Serra, and I. Duchemin, J. Chem. Phys. 144, 034109 (2016).

${ }^{81}$ E. Rebolini and J. Toulouse, J. Chem. Phys. 144, 094107 (2016).

${ }^{82}$ D. Jacquemin, I. Duchemin, A. Blondel, and X. Blase, J. Chem. Theory Comput. 12, 3969 (2016).

${ }^{83}$ M. J. Frisch, G. W. Trucks, H. B. Schlegel, G. E. Scuseria, M. A. Robb, J. R. Cheeseman, G. Scalmani, V. Barone, B. Mennucci, G. A. Petersson, H. Nakatsuji, M. Caricato, X. Li, H. P. Hratchian, A. F. Izmaylov, J. Bloino, G. Zheng, J. L. Sonnenberg, M. Hada, M. Ehara, K. Toyota, R. Fukuda, J. Hasegawa, M. Ishida, T. Nakajima, Y. Honda, O. Kitao, H. Nakai, T. Vreven, J. A. Montgomery, Jr., J. E. Peralta, F. Ogliaro, M. Bearpark, J. J. Heyd, E. Brothers, K. N. Kudin, V. N. Staroverov, R. Kobayashi, J. Normand, K. Raghavachari, A. Rendell, J. C. Burant, S. S. Iyengar, J. Tomasi, M. Cossi, N. Rega, J. M. Millam, M. Klene, J. E. Knox, J. B. Cross, V. Bakken, C. Adamo, J. Jaramillo, R. Gomperts, R. E. Stratmann, O. Yazyev, A. J. Austin, R. Cammi, C. Pomelli, J. W. Ochterski, R. L. Martin, K. Morokuma, V. G. Zakrzewski, G. A. Voth, P. Salvador, J. J. Dannenberg, S. Dapprich, A. D. Daniels, Ö. Farkas, J. B. Foresman, J. V. Ortiz, J. Cioslowski, and D. J. Fox, Gaussian 09, Revision D.01, Gaussian, Inc., Wallingford, CT, 2009.

${ }^{84}$ Y. Zhao and D. G. Truhlar, Theor. Chem. Acc. 120, 215 (2008).

${ }^{85}$ R. Cammi and B. Mennucci, J. Chem. Phys. 110, 9877 (1999).

${ }^{86} \mathrm{M}$. Cossi and V. Barone, J. Chem. Phys. 115, 4708 (2001).

${ }^{87}$ T. H. Dunning, J. Chem. Phys. 53, 2823 (1970).

${ }^{88}$ T. H. Dunning, J. Chem. Phys. 55, 716 (1971).

${ }^{89}$ M. Caricato, B. Mennucci, J. Tomasi, F. Ingrosso, R. Cammi, S. Corni, and G. Scalmani, J. Chem. Phys. 124, 124520 (2006).

${ }^{90}$ TURBOMOLE V6.4 2012, a development of University of Karlsruhe and Forschungszentrum Karlsruhe GmbH, TURBOMOLE GmbH, since 2007 (1989-2007); available from http://www.turbomole.com.

${ }^{91}$ C. Hättig and F. Weigend, J. Chem. Phys. 113, 5154 (2000).

${ }^{92}$ C. Hättig, Phys. Chem. Chem. Phys. 7, 59 (2005).

${ }^{93}$ X. Blase, C. Attaccalite, and V. Olevano, Phys. Rev. B 83, 115103 (2011).

${ }^{94}$ C. Faber, C. Attaccalite, V. Olevano, E. Runge, and X. Blase, Phys. Rev. B 83, 115123 (2011).

${ }^{95}$ J. L. Whitten, J. Chem. Phys. 58, 4496 (1973).

${ }^{96}$ M. Valiev, E. Bylaska, N. Govind, K. Kowalski, T. Straatsma, H. V. Dam, D. Wang, J. Nieplocha, E. Apra, T. Windus, and W. de Jong, Comput. Phys. Commun. 181, 477 (2010).

${ }^{97}$ K. Krause and W. Klopper, J. Comput. Chem. 38, 383 (2016).

${ }^{98}$ L. Goerigk, J. Moellmann, and S. Grimme, Phys. Chem. Chem. Phys. 11, 4611 (2009).

${ }^{99}$ L. Goerigk and S. Grimme, J. Chem. Phys. 132, 184103 (2010).
${ }^{100}$ D. Jacquemin, A. Planchat, C. Adamo, and B. Mennucci, J. Chem. Theory Comput. 8, 2359 (2012).

${ }^{101}$ C. Daday, C. Curutchet, A. Sinicropi, B. Mennucci, and C. Filippi, J. Chem. Theory Comput. 11, 4825 (2015).

${ }^{102}$ C. A. Guido, D. Jacquemin, C. Adamo, and B. Mennucci, J. Chem. Theory Comput. 11, 5782 (2015).

${ }^{103}$ S. Budzák, A. D. Laurent, C. Laurence, M. Medveď, and D. Jacquemin, J. Chem. Theory Comput. 12, 1919 (2016).

${ }^{104}$ C. C. Kitts, T. Beke-Somfai, and B. Nordén, Biochemistry 50, 3451 (2011).

${ }^{105} \mathrm{~T}$. Mayr and H. Wiltsche, Fluorophores.org - the database of fluorescent dyes and applications, 2011, and at http://www.fluorophores.tugraz.at/ (last accessed February 5, 2016).

${ }^{106}$ H. Du, R. A. Fuh, J. Li, A. Corkan, and J. S. Lindsey, Photochem. Photobiol. 68, 141 (1998), spectra available at http://omlc.org/spectra/ PhotochemCAD/index.html (last accessed February 5, 2016).

${ }^{107}$ C. C. Barker and G. Hallas, J. Chem. Soc. 1961, 1529.

${ }^{108}$ G. Hallas, J. Soc. Dyers Colour. 83, 368 (1967).

${ }^{109}$ G. Hallas, D. E. Grocock, and J. D. Hepworth, J. Soc. Dyers Colour. 86, 200 (1970).

${ }^{110}$ A. S. Ferguson and G. Hallas, J. Soc. Dyers Colour. 87, 187 (1971).

${ }^{111}$ C. Aaron and C. C. Barker, J. Chem. Soc. B 1971, 319.

${ }^{112}$ G. Hallas, K. N. Paskins, and D. R. Waring, J. Chem. Soc., Perkin Trans. 2 1972, 2281.

113 A. S. Ferguson and G. Hallas, J. Soc. Dyers Colour. 89, 22 (1973).

${ }^{114}$ C. C. Barker, M. H. Bride, G. Hallas, and A. Stamp, J. Chem. Soc. 1961, 1285.

${ }^{115} \mathrm{H}$. H. Perkampus, UV/VIS Atlas of Organic Compounds, 2nd ed. (VCH, Weinheim, 1992).

${ }^{116}$ C. C. Barker, M. H. Bridge, and A. Stamp, J. Chem. Soc. 1959, 3957.

${ }^{117}$ C. C. Barker, G. Hallas, and A. Stamp, J. Chem. Soc. 1960, 3790.

${ }^{118}$ G. S. Dodd and G. Hallas, J. Chem. Soc., Perkin Trans. 2 1973, 2151.

${ }^{119}$ D. E. Grocock, G. Hallas, and J. D. Hepworth, J. Chem. Soc., Perkin Trans. 2 1973, 1792.

${ }^{120}$ F. C. Adam, J. Mol. Spectrosc. 4, 359 (1960).

${ }^{121}$ J. Griffiths and R. Cox, Dyes Pigm. 42, 29 (1999).

${ }^{122}$ A. Ghanadzadeh, A. Zeini, A. Kashef, and M. Moghadam, J. Mol. Liq. 138, 100 (2008).

${ }^{123}$ S. Basu, D. Ray, and B. B. Bhowmik, Indian J. Chem. 40A, 460 (2001).

${ }^{124}$ M. A. Rauf, A. A. Soliman, and M. Khattab, Chem. Cent. J. 2, 19 (2008).

${ }^{125}$ L. Antonov, G. Gergov, V. Petrov, M. Kubista, and J. Nygren, Talanta 49, 99 (1999).

${ }^{126}$ M. Vogel, W. Rettig, R. Sens, and K. H. Drexhage, Chem. Phys. Lett. 147, 461 (1988).

${ }^{127}$ A. Albert, J. Chem. Soc. 1965, 4653.

${ }^{128}$ I. Duchemin, D. Jacquemin, and X. Blase, J. Chem. Phys. 144, 164106 (2016).

${ }^{129}$ J. Li, G. D'Avino, I. Duchemin, D. Beljonne, and X. Blase, J. Phys. Chem. Lett. 7, 2814 (2016). 